\title{
A Discourse Study of Cognitive Frame Construction of 'China' in American Economic News
}

\author{
Wenhui Yang ${ }^{1}$, Qichao Liang ${ }^{2} \&$ Kaiyue Zhen ${ }^{3}$ \\ ${ }^{1}$ International College, Guangdong University of Foreign Studies, Guangzhou, China \\ ${ }^{2}$ English Department, Hong Kong Baptist University, Hong Kong, China \\ ${ }^{3}$ Sauder School of Business, University of British Columbia, Vancouver, Canada \\ Correspondence: Wenhui Yang, International College, Guangdong University of Foreign Studies, Baiyun Dadao Bei \\ 2\#, Baiyun District, Guangzhou, Guangdong, China. Tel: 86-20-3620-9685.
}

Received: September 4, 2015

Accepted: October 13, 2016

Online Published: October 25, 2016

doi:10.5430/elr.v5n4p7

URL: http://dx.doi.org/10.5430/elr.v5n4p7

\begin{abstract}
This study delves into the complicated yet rewarding examination of the cognitive frame construction and the evoking established frame to interpret China and its economy in American Economic Newspapers. It aims to demystify how linguistic expressions, especially stimuli, influence discourse consumers' cognition and framing process of a relative object, event and phenomenon in the world. Drawing insights from empirical data in China-related American economic news (CAEN) discourse, the authors adopt Force Dynamics Model (Talmy, 1988, 2000) to illustrate the cognitive frame and its framing process that news discourse constructs. The analyses demonstrate that the employment of Force-dynamic stimuli in CAEN discourse will cause news consumers/readers to conceptualize China as being either a weak and ineffectual power or a ferocious and vicious force. These recurring linguistic stimuli, therefore, construct fixed frames in the mind of the discourse consumers and these frames are used to help them interpret and understand an object, event or a phenomenon in a pejorative light. Consequently, the framed knowledge can be used to manipulate discourse consumers' conception and behavior. The study enriches the existing body of work on cognitive linguistic analysis to discover the relationship between language and cognition, and interpreting the construction process of cognitive frame.
\end{abstract}

Keywords: CAEN discourse, Cognitive frame, Conceptualization, Force dynamics, Linguistic stimulus

\section{Introduction}

Cognitive science is an interdisciplinary scientific study of the mind and its processes (Norman, 1980). It examines what cognition is, what it does and how it works. Many of the processes that are essential to social cognition - attribution, perception, stereotyping, and so on - involve language in some manner (Holtgraves \& Kashima, 2008). The language that people use to communicate with one another on their beliefs, perceptions and stereotypes projects and reflects the ideas they wish to communicate. Therefore, one can argue that the ideas that people generate are mediated in part by language. In this sense, language is a tool for implementing social cognition (Semin, 2000), and much social cognition is acquired through the use of language (Holtgraves, 2002). However, the relationship between linguistic expressions and the cognition of such expressions by discourse consumers is complicated. This is such an elusive concept to which there may not be a definitive answer depending on the views one takes. The investigation of such relationships could prove to be a worthwhile endeavor. Because language is overt and cognition is covert, the relationship is not always easily perceptible to everyone. Such a missing link on the knowledge chain is often exploited by those who possess this knowledge and abuse it to serve their own agendas (van Dijk, 2006). In terms of information dissemination, mass media (e.g. newspapers) possess one of the most far-reaching influences and powers. With different values, belief systems and institutional agendas, news discourse producers (reporters and editors) either deliberately or inadvertently influence (van Dijk, 1992) the discourse consumers' (i.e. news reader) cognition and interpretation of objects, events, phenomena and so on.

Among the different processes of social cognition, frame construction or framing is arguably one of the most widely studied cognitive processes (Vliegenthart \& Zoone, 2011). In a very general sense, the internal, conceptual structure of human cognition is called a frame (Wendland, 2010). Framing is thus the process of constructing frames. The practice of framing is of interest to this study because of its potential to provide insights into the various forms of 
interpretation that are circulated in the society. Therefore, the attempts and willingness to explore and understand the cognitive frame construction of a specific subject or target from a specific society and community will ultimately enrich the depth of media discourse study. In this study, the authors will investigate:

How are China and its economy linguistically portrayed and framed in CAEN discourse?

How can linguistic expressions contribute to the investigation of the cognitive frame construction and framing process used in news discourse?

The reason for choosing China as the target of research is because its ascension to economic and political prominence continues. China is gradually becoming a great emerging economic force on the global stage that challenges the economic dominance of the United States. It will be interesting to examine how China is portrayed in the American news media, since economy is at the center of this power competition between the two nations. To demystify and understand the framing of China in China-related American economic news (CAEN) discourse is the essential element of interpretation of cognition and its reflection in linguistic behavior of a specific society.

\section{Literature Review}

\subsection{Cognitive Frame Construction}

A frame is an interpretative schema that simplifies and condenses the world by selectively punctuating and encoding objects, situations, events, experiences and sequences of action (Snow \& Benford, 1992), thus, organizing experience and guiding action by rendering events or occurrences meaningfully. (Snow et al., 1986). It serves as a psychological device that offers a perspective and manipulates salience to influence subsequent judgment (Rhoads, 2004). In discourse studies, language expressions not only highlight individual concepts, but also specify certain perspectives from which the frame is viewed. Such notions are developed and employed in other research fields, particularly artificial intelligence and cognitive psychology. Initially, frame is applied to the research of human memory by psychologists. Frederick Bartlett (1932) proves that human's understanding and memory are influenced by expectation, which is shown through certain schema, while Marvin Minsky (1975), in his study of artificial intelligence, presents frame as a cover term for a data-structure representing a stereotyped situation. He prefers the term 'frame' to 'schema', and further develops his ideas about how the human mind really works by presenting mind-frames that utilize pictures and language (Minsky, 1985). Other researchers have further explored the concept of frame in their respective field. Among them, Rucker et al. (2008) adopt the theory of cognitive frame to study the difference in framing one-sided messages and two-sided messages. They examine how, with almost no difference in the content of a message, framing the message in different ways results in different attitudes towards the message and how to take advantage of this in message framing.

Framing is very commonly used in political discourse to effect persuasion. In a study of political disputes in the 2008 American presidential campaign, Entman $(1993,2010)$ provides evidence to the claim that slanted framing is the result of the interaction of real world developments, cultural norms, and journalistic decision. The results of his study also suggest that although slanted framing creates unbalanced news, such framing can shift over time. Hänggli and Kries (2012) discuss the three most important strategic framing choices by political actors of direct-democratic campaigns in their study of frame construction and frame promotion. They find that the politicians pay attention to different forms of political campaigns and the campaign dialogues do not disappear over the course of the campaign. While Fillmore (1982:116) sees a frame as '(a) domain of vocabulary whose elements somehow presuppose a schematization of human judgment, and behavior, involving notions of worth, responsibility, judgment etc., such that one would want to say that nobody can really understand the meanings of words in the domain who does not understand the social institutions or the structures experience which they presuppose', Fischer (2010b:187) proposes 'constructions are form-meaning pairs which flexibly represent the variable characteristics of larger units with different degrees of schematization.' Hence, frame and construction are both anchored in the cognitive linguistics paradigm and as such subscribe to meaning being grounded in readers' and hearers' information inputs and social interactive experience. 


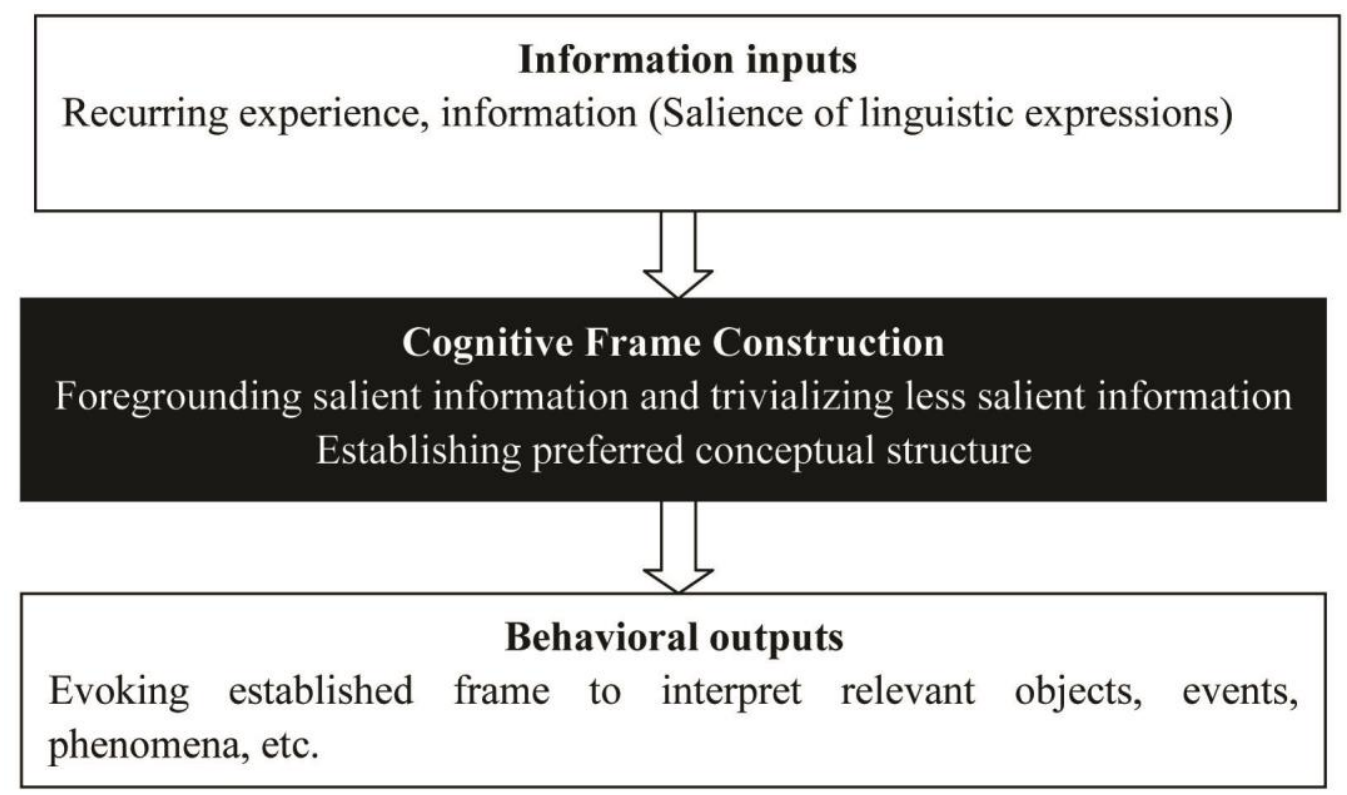

Figure 1. The process of cognitive frame construction (Johnston \& Noakes, 2005)

The process of cognitive frame construction can be viewed as a 'black box'. Communicators put the experiences and information they received into the box, and extract certain processed information from this box to help them perceive and make sense of the world (Johnston \& Noakes, 2005). However, the content of the black box is not readily available to communicators. In order to understand what is going on in that box, linguists and communication researchers need to investigate its contents - the internal conceptual structures.

As for media cognition studies, information inputs from news discourse are language-mediated. The salience of certain linguistic expressions influences the cognitive frame of the news readers by foregrounding salient information and trivializing less salient information (Johnston \& Noakes, 2005). This inclusion and exclusion of information (De Vreese, 2005) thus prompts the construction of a fixed and preferred cognitive frame. This cognitive frame will, then, be evoked or activated to interpret relevant objects, events, phenomena etc. from a fixed perspective (Valkenburg et al., 1999), which impacts directly or indirectly people's interaction with the society and in the society.

\subsection{Force Dynamics}

Societal interaction requires the exertion of force. Johnson (1987) claims that such force is everywhere, and our daily reality is one massive series of forceful causal sequences. Consequently, in order to comprehend our experience, we have to recognize the importance of structures of force. Force dynamics, first proposed by Talmy (1988), is a theory of cognitive linguistics, which concerns the exertion and resistance of a force, the overcoming of such a resistance, and the like. The semantic category of Force Dynamics pervades language on several levels. Not only does it apply to expressions in the physical domain like leaning on or dragging, but it also plays an important role in expressions involving psychological forces (e.g. wanting or being urged). Recently, the concept of Force Dynamics can be extended to discourse.

\subsubsection{Components of Force Dynamic Schemas}

Force Dynamics helps language to structure conceptual materials and organize meanings (Talmy, 1988; 2000; 2006). Expressions can exhibit a Force Dynamic pattern or be Force-Dynamically neutral. A sentence like 'The door is closed' is Force-Dynamically neutral, because there are no forces opposing each other. The sentence 'The door cannot open', on the other hand, exhibits a Force Dynamic pattern: apparently the door has some tendency toward opening, but there is some other force preventing it from being opened (e.g., it may be jammed).

To schematize the possible force patterns, Talmy (1988) uses a schema system to represent the basic elements involved, as shown in Figure 2 below: 
(a)

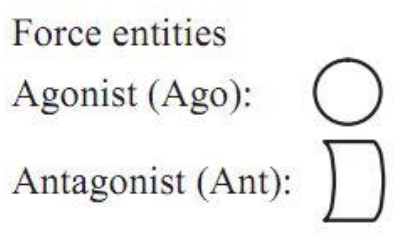

(c) Balance of strengths

stronger entity: +

weaker entity: - (b)

Intrinsic force tendency

toward action:

toward rest:

(d)

Resultant of force interaction

action:

rest:

Figure 2. Elements of force dynamics (Talmy, 1988)

The focal force entity is called the Agonist (Ago) and the force entity opposing it is the Antagonist (Ant). In the example, the door is the Agonist and the force preventing the door from being opened is the Antagonist.

Force entities have an intrinsic force tendency, either toward action or toward rest. In the example, the door has a tendency toward action.

Another factor is the balance between the two forces. The forces are out of balance by definition. One force is therefore stronger or weaker than the other. In the example, the Antagonist is stronger, since it holds back the door. (Talmy, 1988; Hart, 2011)

The outcome of the Force-Dynamic scenario depends on both the intrinsic tendency and the balance between the forces. The result is represented by a line beneath Agonist and Antagonist. The line has an arrowhead if the outcome is action and a large dot if the outcome is rest. The sentence 'The door cannot open' can be Force-Dynamically represented in Figure 3.

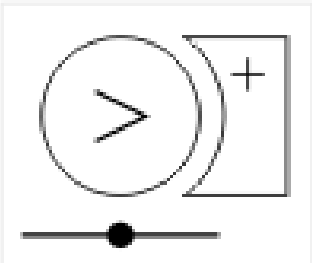

Figure 3. Force-dynamic schema of 'The door cannot open' (Talmy, 1988)

Utilizing these basic components of Force Dynamics, the authors will examine the complex Force-dynamic Patterns (FDPs) to achieve rewarding results concerning cognitive frame construction.

\subsubsection{Force-dynamic Patterns}

\section{a) Steady-state Force-dynamic Patterns}

With the basic concepts of the theory being introduced in section 2.2.1 (see Figure 2), it is possible to characterize the four most basic FDPs which involve steady-state opposition. They are presented in Figure 4 and the examples given below correspond with these schemas.

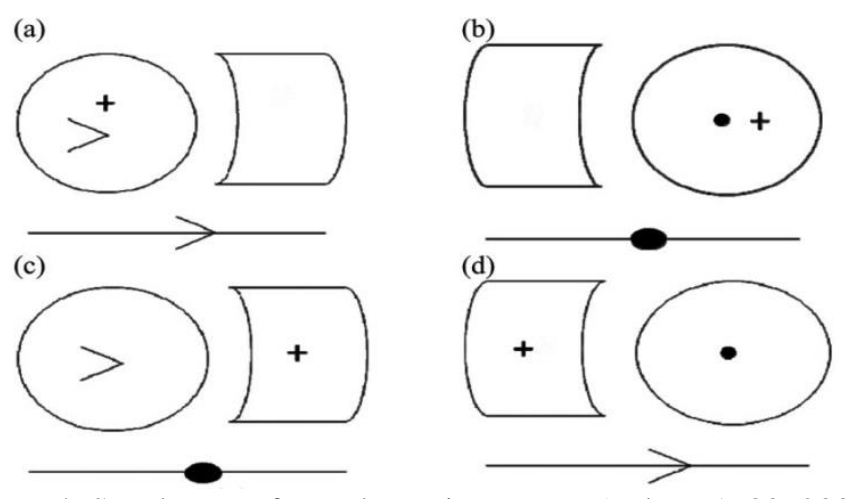

Figure 4. Steady-state force-dynamic patterns (Talmy, 1988; 2000)

a. The ball kept rolling despite the stiff grass.

b. The shed kept standing despite the gale wind blowing against it. 
c. The log kept lying on the incline because of the ridge there.

$\mathrm{d}$. The ball kept rolling because of the wind blowing on it.

The patterns in (a) and (b) are of a 'despite' type in which the Ago realizes its intrinsic force tendency in spite of some force opposing it: either by continuing to move (a) or by continuing to stay in place (b). 'Despite' in (a) and (b) becomes the active linguistic stimulus for the force realization of Ago. In contrast, (c) and (d) are both of a 'causative' kind in which the Ago is unable to realize its intrinsic force tendency: either because it is caused to come to a halt (c) or because it is caused to move (d) (Hart, 2011). Therefore, 'because of' as the 'causative' kind becomes the passive linguistic stimulus for the force realization of Ago.

Table 1. Basic steady-state force-dynamic patterns (Talmy, 1988)

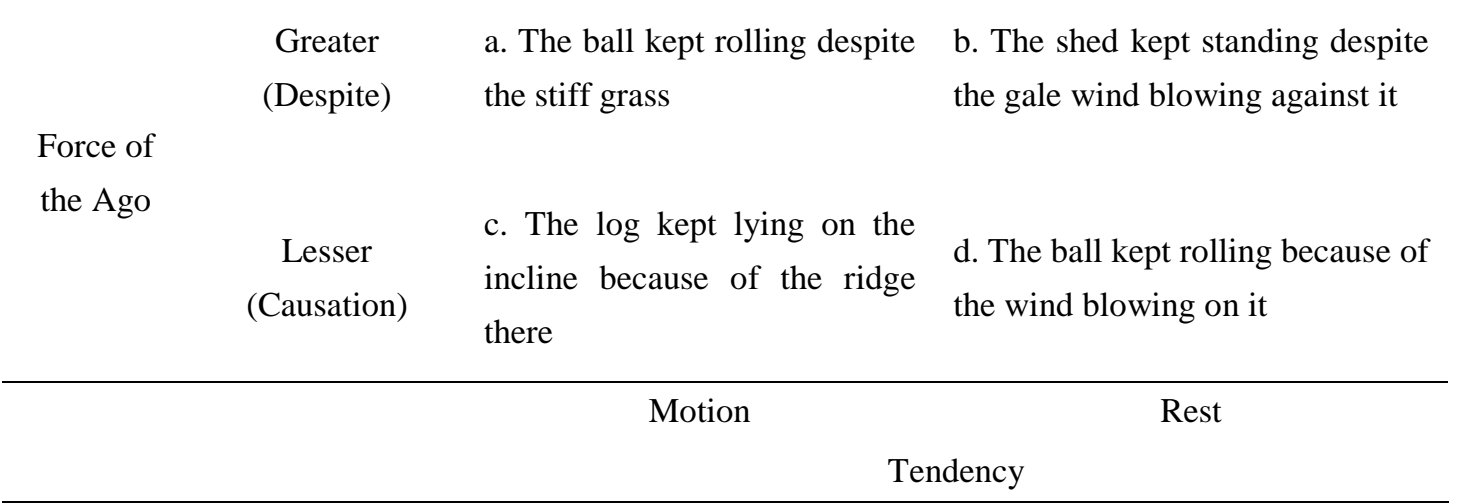

\section{b) Shift-in-state Force-dynamic Patterns}

In addition to the four steady-state schemas, there are four shift-in-state of opposition schemas. They are invoked when another variable is introduced: changing mode over time either with entering or leaving force. In this type of changing pattern, the Antagonist, rather than impinging steadily on the agonist, or instead enters or leaves this state of impingement (Hart, 2011), is presented in Figure 5. The arrow indicates whether the antagonist is entering or leaving the current state, and a slash on the resultant line separating the before and after states of activity (Tamly, 1988).
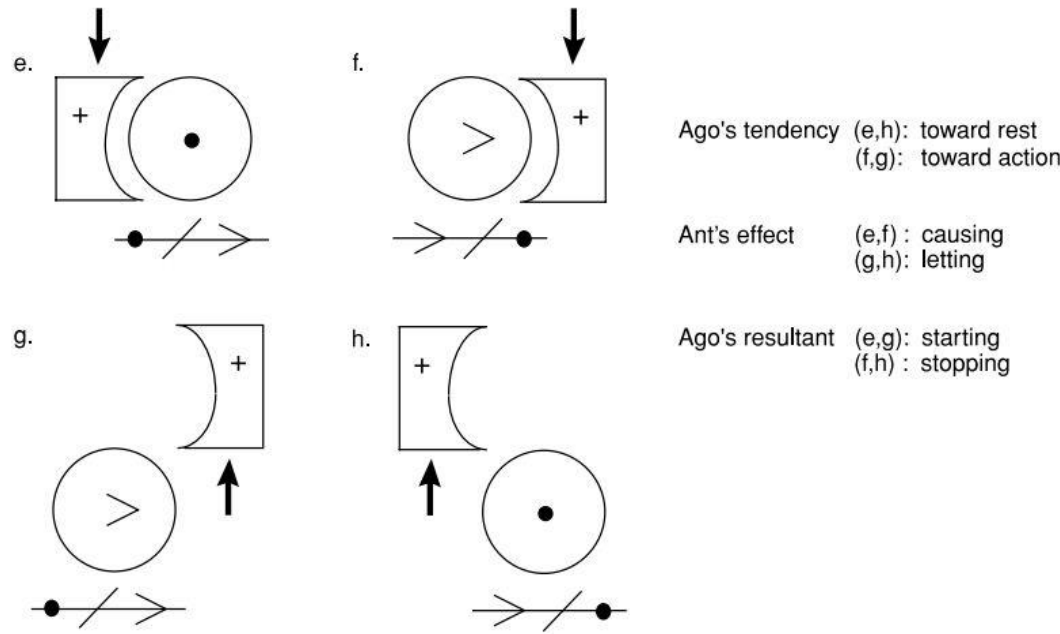
Ago's resultant $(e, g)$ : starting
$(\mathrm{f}, \mathrm{h})$ : stopping

Figure 5. Shift-in-state force-dynamic patterns (Talmy, 1988; 2000)

e. A gust of wind made the pages of my book turn.

f. The appearance of the headmaster made the pupils calm down.

g. The breaking of the dam let the water flow from the storage lake.

h. The abating of the wind let the sailboat slow down.

The patterns in (e) and (f) are of an onset 'causative' type, realized by 'made', in which a stronger Ant not previously in place comes into position against a weaker Ago to prevent it from realizing its intrinsic tendency: either by causing 
it to move (e) or by causing it to come to a halt (f) (Talmy, 1976). Hence, linguistically, 'made' or its alike lexical devices form the active linguistic stimuli of Ant against Ago. In contrast, (g) and (h) are of an onset 'letting' type where a stronger Ant previously in place leaves its state of impingement, thus allowing the weaker Ago to realize its intrinsic tendency either toward action (g) or rest (h) (Hart, 2011). In this case, 'letting' becomes the linguistic passive linguistic stimuli of Ant against Ago.

Table 2. Shift-in-state force-dynamic patterns (Talmy, 1988)

\begin{tabular}{cll}
\hline $\begin{array}{l}\text { Entering, } \\
\text { causation }\end{array}$ & $\begin{array}{l}\text { e. A gust of wind made the pages } \\
\text { of my book turn }\end{array}$ & $\begin{array}{l}\text { f. The appearance of the } \\
\text { headmaster made the pupils calm } \\
\text { down }\end{array}$ \\
$\begin{array}{c}\text { Leaving, } \\
\text { letting }\end{array}$ & $\begin{array}{l}\text { g. The breaking of the dam let the } \\
\text { water flow from the storage lake }\end{array}$ & $\begin{array}{l}\text { h. The abating of the wind let the } \\
\text { sailboat slow down }\end{array}$ \\
\hline \multicolumn{4}{c}{ Motion } \\
\end{tabular}

The examples of the different patterns in section 2.2.2 given above are basic forces existing in a natural environment. However, since physical force is ubiquitous, these patterns can also be extended to discourse analysis. For example, in the sentence 'But after watching [asylum numbers ${ }_{\mathrm{Ago}}$ ] continue to rise despite [a raft of reforms ${ }_{\mathrm{Ant}}$ ], Mr. Blunkett yesterday resurrected the idea ...' the linguistic expressions in bold suggest that this sentence manifest a force dynamic pattern (see 'a' in Figure 4 and Table 1) with the Ago (asylum numbers) being the stronger entity over Ant (a raft of reforms), and realizing its intrinsic tendency toward action (rise). A raft of reforms presents a barrier to the process of immigration, but asylum numbers nevertheless continue to increase (Hart, 2011).

FDPs and their linguistic features in this section provide a theoretical foundation and holistic frame to investigate how China is cognitively portrayed and framed in the American economic news discourse.

\section{Data and Research Method}

The data for the present study is composed of existing and authentic American economic news reports which were published in three major American newspapers, including Wall Street Journal, USA Today and New York Times. The data from these newspapers are collected from ProQuest's newspaper database by multiple advanced searches. The general information of the data is given in Table 3, with all of the news items listed in the Appendices.

Table 3. Collected news items

\begin{tabular}{cc}
\hline Publication & Number of Collected News Items \\
\hline Wall Street Journal & $33(\mathrm{Feb}, 1995-$ Feb, 2012) \\
USA Today & $3(\mathrm{Jan}, 2000-$ Dec, 2006) \\
New York Times & $8($ Apr, 1999 - Dec, 2011)
\end{tabular}

The reason for choosing these three publications is that they are the three largest newspapers in the U.S. in terms of national weekday circulation (Perez-Pena, 2009). The discrepancy of the number of news items from each newspaper is random. When selecting data, the source from which they come is not taken into account. A possible reason for Wall Street Journal taking the lion's share of the news items collected is that Wall Street Journal is more business and economy oriented than the other two newspapers.

Data collection is achieved by utilizing multiple advanced searches in ProQuest's newspaper database. The authors use keyword China combined with economy related terms such as economy, business, finance and so on to get search results. Since the present study is an empirical one, primarily conducted by qualitative discourse analysis, news items are selected randomly and read through by the authors to collect relevant linguistic devices. Since the data and linguistic devices are huge, the authors will only select the linguistic elements that related to the manifestation of Force-dynamic Patterns and their schemas, leaving out the data that are Force-dynamically neutral. Two major patterns, steady-state and shift-in-state, and each of their four sub-patterns will be employed. By investigating these patterns and how they are manifested in the linguistic data, we could get a better glimpse at the inner workings of human cognition and understand how the cognitive frames of a target, such as China, are constructed in the American economic news discourse. 


\section{Analysis of Force-dynamic Elements in the American Economic News Discourse}

A basic force dynamic schema includes four factors: The force entity that is in focus is called the Agonist (represented by the circle) and the force entity opposing it is the Antagonist (represented by the rectangle). Force entities have an intrinsic force tendency, either toward action (represented by the arrow) or toward rest (represented by the dot). A third relevant factor is the balance between the two forces. The forces are out of balance by definition. One force is therefore stronger (the plus sign) or weaker (the minus sign, usually omitted) than the other. The outcome of the Force-Dynamic scenario depends on both the intrinsic tendency and the balance between the forces. The result is represented by a line beneath Agonist and Antagonist. The line has an arrowhead if the outcome is action and a large dot if the outcome is rest. These basic concepts are used to construct two kinds of Force-dynamic patterns: Steady-state and shift-in-state patterns to help the authors to interpret the conceptual relationship between force and linguistic expression.

\subsection{Steady-state Force-dynamic Patterns}

One major FDP is steady-state patterns. They are called steady-state because there is no force entering and leaving the schema. In this part the authors try to use this pattern to help uncover the conceptual meanings in linguistic expressions. The agonist and antagonist are marked when applicable.

\section{a) Agonist realizes its intrinsic tendency towards action, agonist>antagonist}

In pattern (a), Ago is the stronger force; it realizes its intrinsic tendency towards action. This pattern is a 'despite' type which suggests a 'failure to prevent' relation between Ago and Ant, functioning as a negative stimulus and lets ago continue to move.

(a)

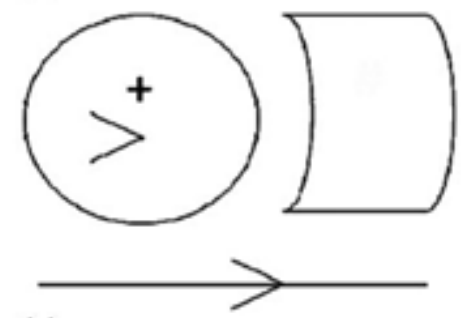

Figure 6. Steady-state force-dynamic pattern (a)

Example 1

[Pirated movies, music and software Ago] remain widely available in China despite [repeated vows of government crackdowns Ant . (USA Today - Item 2)

Example 2

China's Bubble Is Defying Beijing; [Stocks ${ }_{\text {Ago }}$ ] Push Higher Despite [Measures to Cool Investors' Enthusiasm Ant]. (Wall Street Journal - Item 17)

In both Example 1 and 2, the stronger forces were the agonists. They realized their intrinsic tendency toward action against the force exerted by the antagonists after the negative stimulus 'Despite'. One of the advantages of steady-state FDP is that it establishes a binary system of an agonist and an antagonist, therefore, making it easier to uncover the conceptual overtones of the discourse. In Example 1, even though China vowed repeatedly to beat piracy, it is not powerful enough to realize its promise, by using "despite", China is projected and construed as one who does not make real effort to honor its promise, or who is incompetent in handling its task to resolve the issue, letting illegal behavior and products roam free. In Example 2, "despite" implicates that although China has made an effort to resolve the problem of causing bubble, it is perceived (in the news) not only as unwilling to solve the problem, but also as leaving the situation out of control and even causing backfires.

\section{b) Agonist realizes its intrinsic tendency towards rest, agonist>antagonist}

In pattern (b), Ago is the stronger force; it realizes its intrinsic tendency towards rest. This pattern is a 'despite' type which suggests a 'success at resistance' relation between Ago and Ant, working again as a negative stimulus. This time, ago continues to stay in place. 


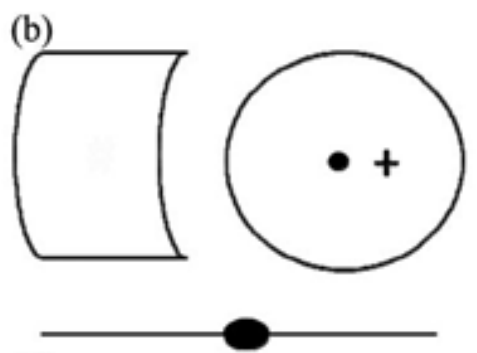

Figure 7. Steady-state force-dynamic pattern (b)

\section{Example 3}

But the [yuan ${ }_{\text {Ago }}$ ] has hardly moved in the nearly three months since then, despite [China's promises to shift toward greater flexibility Ant]. (Wall Street Journal - Item 18)

Example 4

Despite [unprecedented market reforms Ant, [China's government Ago] still strives to meet the Confucian obligations of stability and harmony among the people, analysts say. (Wall Street Journal - Item 19)

In Example 3 and 4, the stronger forces were also the agonists. They realized their intrinsic tendency toward 'rest' state against the force exerted by the antagonist after the negative stimulus 'Despite'. Example 3 is in some way the opposite of Example 1. They both have stronger agonist but with different force tendencies. Yuan has the tendency towards 'rest' state, which is not what most of the world wants. Even though China has promised to make it more flexible, it has hardly moved for months. Similar to Example 1, China is construed as one who does not honor the deal it made. In Example 4, although China has experienced great market reforms, the government's adherence to Confucianism is much stronger. By still trying to uphold traditional Confucius teaching, China here is construed as one who cannot evolve with the times. Even though its economy is catching up with the world, China is still perceived as too conservative.

\section{c) Agonist does not realize its intrinsic tendency towards action, agonist< $<$ antagonist}

In pattern (c), Ant is the stronger force; Ago does not realize its intrinsic tendency towards action. This pattern is a 'causation' type which suggests a 'success at prevention' relation between Ago and Ant, becoming a positive stimulus, through which ago is caused to a halt.

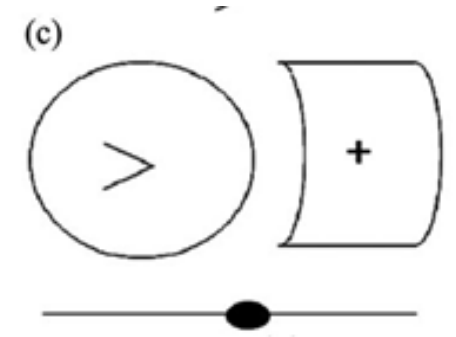

Figure 8. Steady-state force-dynamic pattern (c)

\section{Example 5}

Critics allege that [Chinese-government interference in the market ${ }_{\text {Ant }}$ ] has $\underline{\text { kept }}$ the [yuan Ago $_{\text {at an }}$ artificially $\underline{\text { low level, }}$ rendering Chinese imports unfairly cheap relative to other countries' goods. (Wall Street Journal - Item 7)

In Example 5, the stronger force is the antagonist. The agonist's intrinsic tendency was not realized because of the opposing force of the antagonist. Here, yuan is implied to have the tendency towards action: to change flexibly. However, the Chinese government interference was proposed to be more powerful and be able to 'keep it at a low level' which becomes a positive stimulus to stop the force and cause a halt. China was thus framed as the subject who acted in its own interest to impede the natural development of others.

\section{d) Agonist does not realize its intrinsic tendency towards rest, agonist < antagonist}

In pattern (d), Ant is the stronger force; Ago does not realize its intrinsic tendency towards rest. This pattern is a 'causation' type which suggests a 'failure to resist' relation between Ago and Ant. Ago is caused to move. 


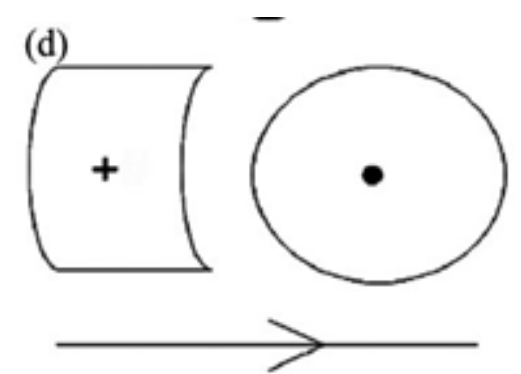

Figure 9. Steady-state force-dynamic pattern (d)

Example 6

In China, 1990 census data show that rural regions lost [residents ${ }_{\text {Ago }}$ ] to the lure of [a strong labor market ${ }_{\text {Ant }}$ ] in the industrial coastal provinces during the previous five years. All figures are in thousands. (New York Times Item 6)

\section{Example 7}

Not long ago Australia and China regarded each other with suspicion. But through newfound diplomatic finesse and the seemingly irresistible lure of [its long economic expansion ${ }_{\text {Ant }}$ ], [Beijing ${ }_{\text {Ago }}$ ] has skillfully turned around relations with Australia, America's staunchest ally in the region. (New York Times - Item 7)

In Example 6 and 7, the stronger force is the antagonist. The agonist's intrinsic tendency is not realized because of the opposing force of the antagonist. Their Force-dynamic pattern is the opposite of Example 5 in terms of force tendency. They are quite different because in both Example 6 and 7, the antagonists are not exactly themselves, but the idea, the temptation that they represent. In both cases, the lure of the two antagonists are too irresistible and function as a positive stimulus to enforce the two agonists to give in to the temptation of antagonists. In Example 7, China is depicted to forego its issues with Australia in light of its future expansion. The lure is so irresistible that it turned around relations with Australia. China is therefore construed as the subject who is willing to do anything for its own interest and is very sneaky and skillful at scheming.

\subsection{Shift-in-state Force-dynamic Patterns}

From the data, another FDP patterns regarding force changes are also identified. These patterns are called shift-in-state FDP patterns because there is a force entering or leaving the schema.

\section{e) A stronger force enters. State shifts from rest to action. Force entering $\downarrow$}

In pattern (e), a stronger force enters to cause the state to shift from rest to action. This pattern is a 'causation' type which suggests that the entering of a stronger force causes the weaker Ago to come move.

(e)

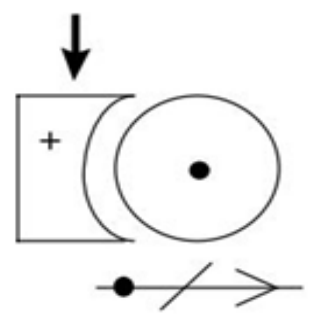

Figure 10. Shift-in-state force-dynamic pattern (e)

\section{Example 8}

They point to a bill that passed the House last month that would make easier for [domestic industries ${ }_{\text {Ago }}$ ] to win cases against China based on the argument that Beijing's restraint of its currency subsidizes its exports. (Wall Street Journal - Item 20)

Example 9

Tom Hopson, president of Five Rivers Electronic Innovations LLC in Greeneville, Tenn., said the heightened duties "will allow [us ${ }_{\text {Ago }}$ ] to compete against a flood of unfairly priced imports (Chinese products)." (Wall Street Journal - Item 21) 


\section{Example 10}

Beijing's chief trade negotiator said yesterday that his country and the U.S. are "very close" to a deal that would allow [China ${ }_{\text {Ago }}$ ] to enter the World Trade Organization, but that differences could still scuttle an accord. (Wall Street Journal - Item 22)

In shift-in-state Force-dynamic patterns, the Ant is often left implicit. The ago is now the direct object of the relevant active verbs, such as 'make' and 'allow'. In all three examples, the state of the ago is originally rest; however they have an intrinsic tendency towards action. With a stronger force entering, active verbs make it possible for the ago to realize its intrinsic force tendency. In Example 8, the passing of a bill is the force entering the scenario. The domestic industries were originally at rest or inaction, although they have tendencies towards action, they are not strong enough to take on China. And now the passing of the bill to some degree enables them to take an action, to realize their intrinsic force tendencies. In Example 9, the American company is originally rest with an intrinsic tendency towards action. After the implementation of the emphasized duties (the entered force), they are enabled to compete with the Chinese products with which they originally cannot compete. In this way, China is construed as being the unfair competitor of American companies; the imposing of the heightened duties is viewed as legitimate and a just means against an unjust rival. In Example 10, China is originally inactive (cannot enter the World Trade Organization) although it has the tendency of action (such as join the World Trade Organization). It is only after a deal being made with the U.S. (the entered force) that China can finally realize its intrinsic force tendency. China is thus framed as a weak entity compared with the U.S. since only the U.S. has the power to help China to get in the World Trade Organization and China can only be at its mercy.

\section{f) A stronger force enters. State shifts from action to rest. Force entering $\downarrow$}

In pattern (f), a stronger force enters to cause the state to shift from action to inaction. This pattern is a 'causation' type which suggests that the entering of a stronger force causes the weaker Ago to come to a halt.

(f)

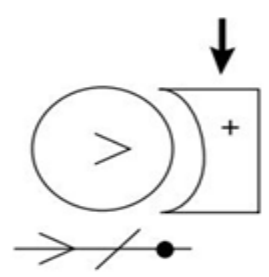

Figure 11. Shift-in-state force-dynamic pattern (f)

\section{Example 11}

In the House, about 100 lawmakers, including 30 Republicans, sent a letter recently to the House leadership asking for a vote on a bill that would allow the [U.S. Ago $_{\text {I }}$ to impose tariffs and other penalties on countries (including and especially China) that undervalue their currency. (Wall Street Journal - Item 23)

In Example 11, the state of the ago is originally in action; however, they have an intrinsic tendency towards rest. With a stronger force entering, the positive stimulus 'allow' makes it possible for the ago to realize its intrinsic force tendency. In this piece of news, China is projected as an offender of law, which the U.S. is now able to punish once the bill gets passed. It is once again an example of China being the unjust subject and the U.S. being the voice of reason.

\section{g) A stronger force leaves. State shifts from rest to action. Force leaving $\uparrow$}

In pattern (g), a stronger force leaves to cause the state to shift from rest to action. This pattern is a 'letting' type which suggests that the leaving of a stronger force allows the weaker Ago to realize its intrinsic tendency to action.

(g)

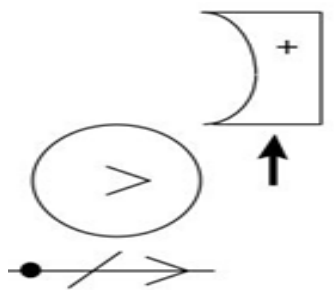

Figure 12. Shift-in-state force-dynamic pattern $(\mathrm{g})$ 


\section{Example 12}

The yuan has appreciated about 8.5\% since China abolished its peg to the dollar in July 2005 and began allowing [it ${ }_{\text {Ago }}$ ] to trade within a certain band each day. (Wall Street Journal - Item 7)

Example 13

But for Washington, the main supplier of arms to Beijing's rivals in Taiwan, the dropping of a European arms embargo also poses a danger: It could cause [European weaponry ${ }_{\text {Ago }}$ ] to be funneled into China's bid for military superiority across the Taiwan Strait. (Wall Street Journal - Item 24)

\section{Example 14}

Geographic barriers have come down for foreigners since China joined the World Trade Organization and had obligations to gradually liberalize its economy, allowing [foreign firms ${ }_{\text {Ago }}$ ] to go deeper in to the country. (Wall Street Journal - Item 25)

In the Example 12 and 13, the state of the ago is originally rest but with an intrinsic tendency towards action. With a stronger force leaving, they are now capable of realizing its intrinsic force tendency by an active or a positive linguistic stimulus. In Example 12, once China abolished its peg to the dollar, the stronger force left the scenario. The 'yuan' was originally in a state towards rest but having an intrinsic tendency towards action. And since the opposing force left, the 'yuan' is free to realize its force tendency (being traded). Here, China is once again construed as one who oppresses something that is supposed to be free and thus framed as an evil figure. In Example 13, European weaponry was originally in a state of rest with tendency towards action. Once the opposing force of embargo left the scenario, the ago is now able to realize its force tendency. Here, China is projected as one who would get its hands on things that will help it achieve superiority, even if it means getting them like drinking from a funnel. In Example 14, the ago was originally in a state of rest with geographical barriers being the opposing force. But when the barriers came down, the force left the scenario, the ago is free to realize its intrinsic force tendency towards action (go deeper into the country). In this piece of news, China is framed as an oppressor who closed off its entrance to shut out potential visitors. The semantics of the word liberalize also adds to this sense of construal.

\section{h) A stronger force leaves. State shifts from action to rest. Force leaving $\uparrow$}

In pattern (h), a stronger force leaves to cause the state to shift from action to rest. This pattern is a 'letting' type which suggests that the leaving of a stronger force allows the weaker Ago to realize its intrinsic tendency to rest.

(h)

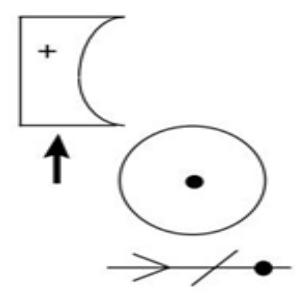

Figure 13. Shift-in-state force-dynamic pattern (h)

Example 15

Government policy changes have thrown China's booming [property market ${ }_{\text {Ago] }}$ into a period of paralysis that some industry executives say will last for several months. (Wall Street Journal - Item 26)

In this pattern, the state of the ago is originally in action; however the ago has an intrinsic tendency towards rest. With a stronger force leaving, it is now capable of realizing its intrinsic force tendency towards rest. In Example 15, the force that is leaving this equation can be easily identified as the change of policy. The ago was originally in a state of action (booming) which is propelled by the original policy. With the change of the policy, the ago is not just put back to its original path of development, but is thrown into a period of immobility. In this way, China's property market is first construed as being in a stagnant state before government intervention and is now miserable without government policy to support it. In the event that the policy is not in its favor, it may even plunge into paralysis.

Through the analyses, one common characteristic of the newspaper's manipulation method becomes clear, that is to create a binary dichotomy of 'positive self and negative other' (van Dijk, 1993). In most of CAEN discourse collected, China is always antagonized as an enemy, a negative existence, while the U.S. is contrasted as a positive force who has to endure and suffer the attack of the negative one(s). China is placed in an antagonizing position. 
Moreover, the analyses indicate that linguistic expressions of active/positive or passive/negative stimuli that exhibit a Force-dynamic pattern are capable of constructing and framing people's cognition, which will be further discussed in the next section.

\section{Discussion}

The cognitive process of human beings is a curious case and yet can prove to be infinitely rewarding once insights are gained into its inner working. It governs the way we perceive the world around us and in turn dictates our behavior and action toward the world. Since cognition is an essential part of our experience as human beings, it is significant to see how people's ideas, perceptions and stereotypes can be identified and interpreted in the language they use. Moreover, language is a powerful tool that we can use and possess; it is how we as social beings connect with one another in order to survive and thrive. As two of the most essential properties that belong to human beings, language and cognition are themselves inseparably connected in a specific society. Language often serves as the medium for our social cognition which dictates how we perceive the world and how we use our language to express that perception and language in turn casts influence on our cognition (Lecheler, De Vreese \& Slothuus, 2009).

In this study, the authors, by applying the force dynamic patterns to analyze the American media on a specific target, uncover an aspect of the relationship between language and cognition which constructs the cognitive frame of that target. The process of cognitive frame construction is viewed as an embedded element in the black box proposed by Johnston and Noakes (2005). News readers or consumers put the experience and information they receive into the box, and extract certain processed information from this box to help them perceive and make sense of the world (Scheufele \& Tewksbury, 2007). The recurring experience and information become salient; this salience of linguistic expressions then influences the cognitive frame of an object, an event or a phenomenon by foregrounding salient information and trivializing less salient information. This inclusion and exclusion of information (De Vreese, 2005) thus prompts the construction of a fixed and preferred cognitive frame which will be evoked or activated to interpret the world around us from a fixed perspective (Valkenburg et al., 1999), i.e. a discourse construction of the cognitive frame, achieved by either with positive or negative stimuli, which further supports the findings of Langacker (2001, 2008) and Fischer (2010a, 2010b) from the perspective of cognitive grammar study.

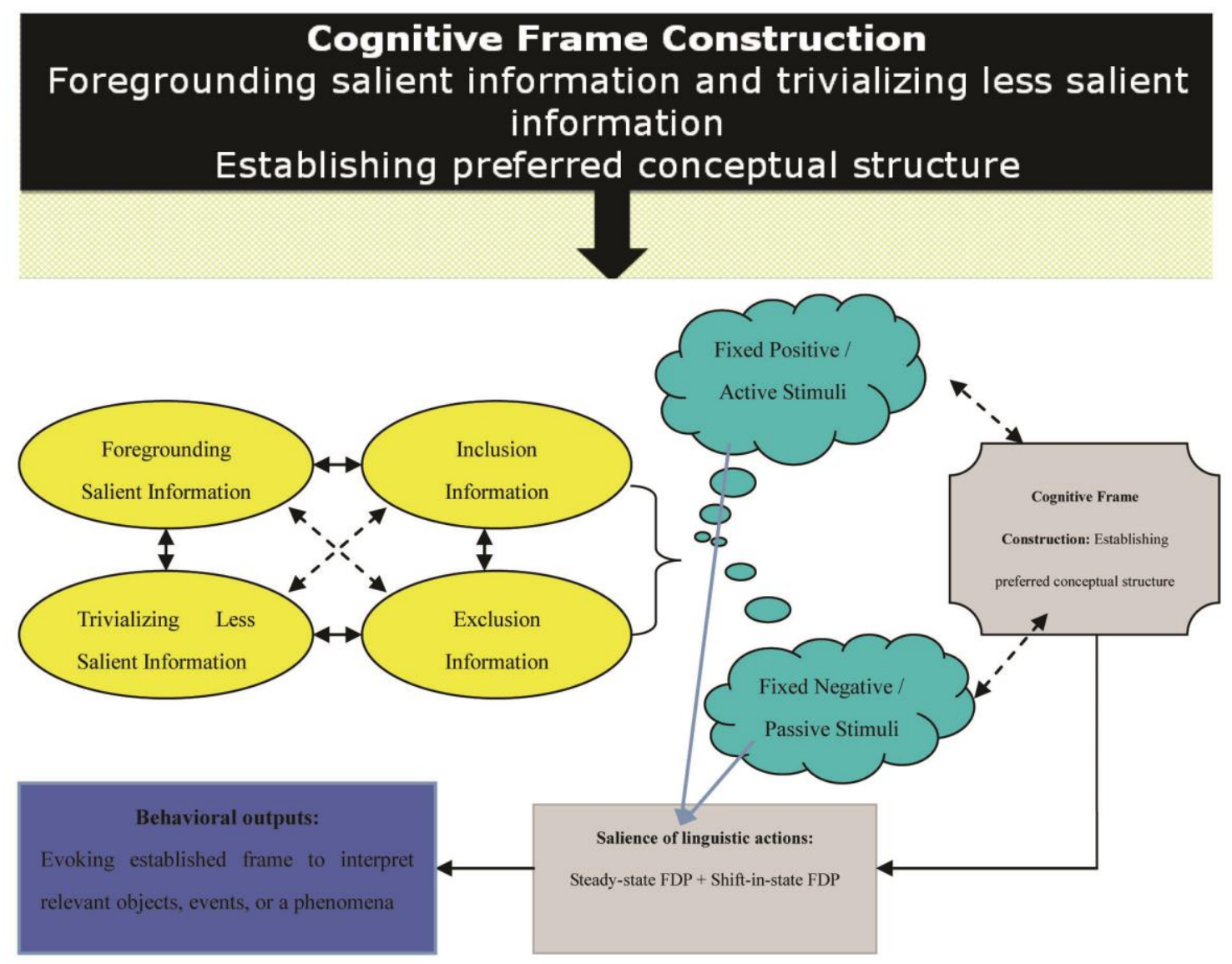

Figure 14. Cognitive construction and its framing process 
In Figure 14, the salience of linguistic expressions that fall under the two conceptual systems of fixed positive and negative stimuli is employed to communicate meaning in a way that is contrary to the benefit of an object, event or phenomenon, reflecting a preferred conceptual structure in CAEN discourse. These recurring expressions enforce or reinforce news consumers' perception of an object, event or a phenomenon to create a fixed cognitive frame in their mind. When we use language to represent ourselves and the world around us, the linguistic choices we select would be an interpretation of what things we perceive. Therefore, what is presented is merely one of the many versions of the reality. In this sense, our language constructs a frame of partial truth and this construction is only one of the many possible constructions (Xin, 2007). This means that the same phenomenon is potentially conceptualized in any number of different ways but that alternative language structures impose particular conceptualizations (Langacker, 1991; 2008). By choosing, either consciously or inadvertently, from different cognitive frames, salience linguistic actions and discourse producers achieve their communication objectives and establish frame to interpret their discursive objects, events and phenomena, such as the image of China in the world. Besides, the investigation of linguistic expressions also indicates that the employment of force dynamic expressions in CAEN discourse can cause news consumers to conceptualize the target reported in news, by applying either positive or negative stimuli, as being either a weak and ineffectual power or a ferocious and vicious force. Such a finding is achieved because the concept of force in Force Dynamic theory is a natural fit for exploring the relations between the two powers, in the case of CAEN discourse, which are China and the U.S. Within the cognitive frame construction in CAEN discourse, news reporters present a stronger force or a weaker one through various linguistic choices.

As an emergent property of public communication, news authors' cognitive constructing and framing processes are not transparent in either the linguistics or the sociolinguistics, but must be inferred from empirical study of discourse in real contexts and from different cultural perspectives. Throughout human history, the antagonized opposition is always dehumanized and treated as less than human, less than their equals. This caused bearing grudges and even killing the other side much easier with less concern about it appropriateness. Such a dehumanization is one central component and approach as well to frame the cognitive construction and frame of the 'positive self, negative other' in a specific society. Issues of political stance, education background and ideology anchored in specific cultural and social contexts, are critical to sociolinguistics of cognition and cognition framing process. That is, we can analyze the linguistic way that culturally and ideologically specific social, institutional and political formations structure people's access to particular linguistic cognition as well as shape the cognition that is attributed to them.

\section{Conclusion}

The cognitive construction and its framing process of an object, event or phenomenon, which are greatly associated with language used in the media, can form people's perception and ideology as well. From a political perspective, ideological manipulation, especially in the form of mass media, is in itself a very politically motivated act (van Dijk, 1995), providing a theoretical base for the grounding of language in discourse and social communication. The present research is an initial attempt to study a complex issue regarding human beings' cognition and its projected and reflected linguistic behavior. We acknowledge the limitations of using a static perspective and believe that interesting insights can be obtained from readers' cognitive feedback across different cultural backgrounds. We also realize cognition research can be approached in ways other than the approach presented here. We thus encourage future research to integrate and consider links to discoursal effects. As news readers, when they consume news they might seek out news reports from a variety of linguistic sources with different discoursal backgrounds and cognitive frames. By selecting alternative source of information, they could learn more from different ways of reporting, and thus develop possibly a different or relatively fixed view of objects, events and phenomena. From a cultural perspective, ideological manipulation, in form of cultural experience that news consumers learn about, might be more sensitive towards the possible power manipulation from that culture and also their own preexisting prejudices, projected by positive and negative linguistic stimuli applied in their discourse. They might perceive foreign culture in a more negative way towards others culture and a positive one towards themselves. However, such a cognitive frame or bias can be changed or even fixed with cognitive interventions such as intercultural linguistic training, in which both news writers and consumers learn to balance their perception and cognition towards others as well as themselves. As Shi (2008) puts it, people should strive to be more 'locally-grounded, globally-minded and multiculturalist' if they want to take part in the global discourse while retaining their own voice, at the same time respecting others from different cultural backgrounds.

\section{Acknowledgment}

This research is supported by the Major Grant of the National Key Research Centers for Philosophy and Social Sciences, Ministry of Education, China (No. 14JJD740011), as well as the MOE Project of the Center for Linguistics 
and Applied Linguistics, Guangdong University of Foreign Studies. The authors would like to extend great appreciation to editors' and reviewers' comments on the revision of the paper. We are also very grateful to Mr. Don Andrus Homer for his proofreading of this paper.

\section{References}

Bartlett, F. (1932). Remembering: A study in experimental and social psychology. Cambridge, UK: Cambridge University Press.

De Vreese, C. H. (2005). News framing: Theory and typology. Document Design, 13(1), 51-62. http://dx.doi.org/10.1075/idjdd.13.1.06vre

Entman, R. M. (1993). Framing: Towards clarification of a fractured paradigm. Journal of Communication, 43(4), 51-58. http://dx.doi.org/10.1111/j.1460-2466.1993.tb01304.x

Entman, R. M. (2010). Media framing biases and political power: Explaining slant in news of Campaign 2008. Journalism, 11(4), 389-408. http://dx.doi.org/10.1177/1464884910367587

Fillmore, C. J. (1982). Frame semantics. In Linguistics in the morning calm (pp. 111-137). Seoul, Hanshin Publishing Co.

Fischer, K. (2010a). Accounting for the role of situation in language use in a cognitive semantic representation of sentence mood. In D. Glynn \& K. Fischer (Eds.), Quantitative methods in cognitive semantics: Corpus-driven approaches (pp. 179-200). Berlin: Mouton de Gruyter. http://dx.doi.org/10.1515/9783110226423.179

Fischer, K. (2010b). Beyond the sentence. Constructions and Frames, 2(2), 185-207. http://dx.doi.org/10.1075/cf.2.2.03fis

Hart, C. (2011). Force-interactive patterns in immigration discourse: A cognitive linguistic approach to CDA. Discourse \& Society, 22(3), 269-286. http://dx.doi.org/10.1177/0957926510395440

Holtgraves, T. M. (2002). Language as social action: Social psychology and language use. Mahwah, NJ: Erlbaum.

Holtgraves, T. M. \& Yoshihisa, K. (2008). Language, meaning, and social cognition. Personality and Social Psychology Review, 12(1), 73-94. http://dx.doi.org/10.1177/1088868307309605

Johnson, M. (1987). The body in the mind: The bodily basis of meaning, imagination, and reason. Chicago: University of Chicago Press.

Johnston, H., \& Noakes, J. A. (2005). Frames of protest: Social movements and the framing perspective. Lanham: Rowman \& Littlefield Publishers.

Langacker, R. W. (1991). Foundations of cognitive grammar, Vol. II: Descriptive application. Stanford, CA: Stanford University Press.

Langacker, R. W. (2001). Discourse in cognitive grammar. Cognitive Linguistics, 12(2), 143-188. http://dx.doi.org/10.1515/cogl.12.2.143

Langacker, R. W. (2008). Cognitive grammar: An introduction. New York: Oxford University Press. http://dx.doi.org/10.1093/acprof:oso/9780195331967.001.0001

Lecheler, S., De Vreese, C. \& Slothuus, R. (2009). Issue importance as a moderator of framing effects. Communication Research, 36(3), 400-425. http://dx.doi.org/10.1177/0093650209333028

Minsky, M. (1975). A framework for representing knowledge. In P. H. Winston (Ed.). The psychology of computer vision (pp. 211-277). New York: McGraw-Hill.

Minsky, M. (1985). The society of mind. New York: Touchstone books/Simon \& Schuster.

Norman, D. (1980). Twelve issues for cognitive science. Cognitive Science, 4(1), 1-32. http://dx.doi.org/10.1207/s15516709cog0401_1

Perez-Pena, R. (2009). U.S. newspaper circulation falls 10\%. New York Times, October 26, 2009.

Rucker, D., Petty, R. \& Briñol, P. (2008). What's in a frame anyway?: A meta-cognitive analysis of the impact of one versus two sided message framing on attitude certainty. Journal of Consumer Psychology, 18(2), 137-149. http://dx.doi.org/10.1016/j.jcps.2008.01.008

Scheufele, D. A. \& Tewksbury, D. (2007). Framing, agenda setting, and priming: The evolution of three media effects models. Journal of Communication, 57(1), 9-20. http://dx.doi.org/10.1111/j.0021-9916.2007.00326.x 
Semin, G. R. (2000). Agenda 2000-Communication: language as an implementational device for cognition. European Journal of Social Psychology, 30, 595-612. http://dx.doi.org/10.1002/1099-0992(200009/10)

Shi, Xu. (2008). Towards a cultural turn in discourse analysis: reasons, objectives and strategies for constructing a Chinese discourse studies paradigm. Journal of Zhejiang University (Humanities and Social Sciences), 38, 131-140.

Snow, D. A., Rochford, E. B., Worden, S. K. \& Benford, R. D. (1986). Frame alignment processes, micromobilization and movement participation. American Sociological Review, 51, 464-482. http://dx.doi.org/10.2307/2095581

Snow, D. A. \& Benford, R. D. (1992). Master frames and cycles of protest. In A. D. Morris \& C. Mueller (Eds.), Frontiers in social movement theory (pp. 133-155). New Haven, CT: Yale University Press.

Talmy, L. (1976). Semantic causative types. In M. Shibatani (Ed.), Syntax and Semantics (vol. 6): The grammar of causative constructions (pp. 43-116). New York: Academic Press.

Talmy, L. (1988). Force dynamics in language and cognition. Cognitive Science, 12(1), 49-100. http://dx.doi.org/10.1207/s15516709cog1201_2

Talmy, L. (2000). Toward a Cognitive Semantics. Cambridge, MA: MIT Press.

Talmy, L. (2006). Cognitive linguistics. In K. Brown (Ed.), Encyclopedia of language and linguistics (pp. 542-546). Oxford, UK: Elsevier. http://dx.doi.org/10.1016/B0-08-044854-2/00351-5

Valkenburg, P., Semetko, H. A. \& De Vreese, C. H. (1999). The effect of news frames on readers' recall and thoughts. Communication Research, 26(5), 550-568. http://dx.doi.org/10.1177/009365099026005002

van Dijk, T. A. (1992). Discourse and the denial of racism. Discourse \& Society, 3, 87-118. http://dx.doi.org/10.1177/0957926592003001005

van Dijk, T. A. (1995). Power and the news media. In D. Paletz (Ed.), Political Communication and Action (pp. 9-36). Cresskill, NJ: Hampton Press.

van Dijk, T. A. (1993). Elite discourses and racism. London: Sage. http://dx.doi.org/10.4135/9781483326184

van Dijk, T. A. (2006). Discourse and manipulation. Discourse \& Society, 17(2), 359-383. http://dx.doi.org/10.1177/0957926506060250

Vliegenthart, R. \& Zoone, L. (2011). Power to the frame: Bringing sociology back to frame analysis. European Journal of Communication, 26(2), 101-115. http://dx.doi.org/10.1177/0267323111404838

Wendland, E. R. (2010). "Framing the frames: A theoretical framework for the cognitive notion of 'frames of reference'." Paper presented at "Translation and Cognition - International Conference on Translation", University of Murcia, Murcia, Spain, June.

Xin, Bin. (2007). The Social and cognitive orientations of critical discourse analysis. Foreign Languages Research, 106(6), 19-24. 


\section{Appendices}

\section{Appendix A: Wall Street Journal}

Item 1) Business World: Another Tricky Landing for the China Trade Lobby.

Holman W. Jenkins Jr.. Wall Street Journal [New York, N.Y] 18 Apr 2001: A.23.

Item 2) How I'll Respond to China's Rising Power.

Romney, Mitt. Wall Street Journal [New York, N.Y] 16 Feb 2012: A.13.

Item 3) Inside Pentagon, a Scholar Shapes Views of China.

Neil King Jr. Wall Street Journal [New York, N.Y] 08 September, 2005

Item 4) High Court Rejects Appeal of Trade-Case Decision.

Anderson, Mark H. Wall Street Journal [New York, N.Y] 03 Oct 2006: A.2.

Item 5) U.S. and China agree to meet next week in fresh attempt to avert a trade war.

Cooper, Helene; Greenberger, Robert S. Wall Street Journal [New York, N.Y] 07 Feb 1995: A2.

Item 6) Politics \& Economics: Punishing China: Will It Fly?; Bills in Congress on Yuan Could Backfire.

John McCary in Washington and Andrew Batson in Beijing. Wall Street Journal [New York, N.Y] 23 June 2007: A.4.

Item 7) The Economy; CAPITAL: China Rewrites Rules for Building Wealth.

Wessel, David. Wall Street Journal [New York, N.Y] 29 Jan 2004: A.2.

Item 8) China Eases Forex Controls on Earnings by Exporters.

Batson, Andrew; Back, Aaron. Wall Street Journal [New York, N.Y] 28 Aug 2010: B.4.

Item 9) The U.S. Stands Up to China's Bullying.

Blumenthal, Daniel. Wall Street Journal [New York, N.Y] 28 July 2010: A.17.

Item 10) China's Aggressive Buyers Suffer Setbacks on Some Overseas Deals.

Gary McWilliams and Evan Ramstad. Wall Street Journal [New York, N.Y] 22 Aug 2006: A.1.

Item 11) World News: China Moves In to Calm Markets' Nerves - Beijing Breaks With Past Strategy and Allows Yuan to Climb for Fourth Day, Signaling Effort to Smooth Global Volatility.

Kazer, William; Browne, Andrew. Wall Street Journal [New York, N.Y] 12 Aug 2011: A.10.

Item 12) Beijing Restrains Growth in Loans But Raises Risks; Some Small Businesses Are Denied Needed Credit; Foreign Investment Endures.

Matt Pottinger and Phelim Kyne. Wall Street Journal [New York, N.Y] 14 July 2004: A.13.

Item 13) Chinomics: The Fallacy of the Beijing Consensus; China's debt-fuelled growth looks remarkably similar to the experience of Brazil in the late 1960s.

Wall Street Journal (Online) [New York, N.Y] 20 June 2010: n/a.

Item 14) China Deepens Push in Canadian Oil.

Welsch, Edward. Wall Street Journal [New York, N.Y] 10 Oct 2011: B.1.

Item 15) The Lonely Fight to Boost the Yuan; U.S. Has Few Asian Allies In Chinese-Currency Spat -- And Isn't Going to the Mat.

Day, Phillip. Wall Street Journal [New York, N.Y] 21 Oct 2003: A.11.

Item 16) China's Bubble Is Defying Beijing; Stocks Push Higher Despite Measures to Cool Investors' Enthusiasm.

Areddy, James. Wall Street Journal [New York, N.Y] 22 May 2007: C.3.

Item 17) U.S. to Be Patient on Yuan in Talks With China.

King, Neil. Wall Street Journal [New York, N.Y] 10 Oct 2005: A.2

Item 18) Remaking the Economy - The American Way: With its Asian neighbors struggling, China's leaders have found a new economic model: the U.S.

By Peter Wonacott. Wall Street Journal [New York, N.Y] 30 Apr 1998: R8. 
Item 19) U.S. to Press China Harder - Beijing's Weak Currency Remains Top Issue; Treasury Report on Yuan Due Friday.

Davis, Bob. Wall Street Journal [New York, N.Y] 11 Oct 2010: A.1.

Item 20) U.S., China Risk New Trade Spat Over Color TVs; Move toward Stiff Duties By Washington Prompts Angry Response in Beijing.

Peter Wonacott in Beijing and Neil King Jr. in Washington. Wall Street Journal [New York, N.Y] 26 Nov 2003 : A.12.

Item 21) China Says WTO Pact Is Close, But It Seeks Clarifications.

Wall Street Journal [New York, N.Y] 29 Sep 1999: A19.

Item 22) Geithner Stuck in the Middle on China; On Capitol Hill, Treasury Secretary Presses Beijing to Boost Value of Its Currency but Pushes Back on Punitive Legislation.

Wall Street Journal (Online) [New York, N.Y] 16 Sep 2010: n/a.

Item 23) International - A Global Journal Report: Europe Builds Ties with China; With Few Historical Rivalries, Sides Embrace Trade, Diplomacy.

David Murphy in Beijing and Shada Islam in Brussels. Wall Street Journal [New York, N.Y] 06 Feb 2004: A.12.

Item 24) Politics \& Economics: China's Inland Frontier Beckons; Big, Lesser-Known Cities Hold Growth Prospects for Foreign Firms.

Leow, Jason. Wall Street Journal [New York, N.Y] 14 Mar 2007: A.4.

Item 25) China's Bid to Defuse Real-Estate Froth Cools Market.

Batson, Andrew. Wall Street Journal (Online) [New York, N.Y] 03 June 2010: n/a.

Item 26) Surface Tensions: As China Grows, So Does Its Long-Neglected Navy; Warship-Buying Spree Prompts New Worry in Washington, Tokyo.

Fairclough, Gordon. Wall Street Journal [New York, N.Y] 16 July 2007: A.1.

Item 27) The Long China View.

Wall Street Journal [New York, N.Y] 20 Apr 2006: A.14.

Item 28) China Can Spur Growth without a Devaluation.

By Craig S. Smith. Wall Street Journal [New York, N.Y] 22 June 1998: A1.

Item 29) Currency Act Is No Smoot-Hawley.

Anonymous. Wall Street Journal (Online) [New York, N.Y] 15 Oct 2011: n/a.

Item 30) The Business: U.S. Attacks China Inc..

Bussey, John. Wall Street Journal [New York, N.Y] 03 Feb 2012: B.1.

Item 31) Secret Weapon: Inside Pentagon, A Scholar Shapes Views of China; Beijing, Mr. Pillsbury Says, Sees U.S. as Military Foe; An Optimist Turns Gloomy; His Direct Line to Top Aides.

King, Neil. Wall Street Journal [New York, N.Y] 08 Sep 2005: A.1.

Item 32) World News: China Gets a Warning on Bubbles in Housing: [1].

Dean, Jason. Wall Street Journal [New York, N.Y] 04 Dec 2009: A.15.

Item 33) World News: Geithner Stuck in the Middle on China - On Capitol Hill, Treasury Secretary Presses Beijing to Boost Value of Its Currency but Pushes Back on Punitive Legislation.

Davis, Bob; Batson, Andrew. Wall Street Journal [New York, N.Y] 17 Sep 2010: A.12. 


\section{Appendix B: USA Today}

Item 1) China appears less likely to devalue its currency: [FINAL Edition].

Wiseman, Paul. USA Today [McLean, Va] 31 Jan 2000: 06B.

Item 2) Force of China's impact grows in USA.

J. Lynch, David. USA Today [McLean, Va] 12 Dec 2006.

Item 3) Pondering investment in China? Take the long view; Be prepared for corrections: [FINAL Edition].

Block, Sandra. USA Today [McLean, Va] 17 Mar 2004: B.05.

\section{Appendix C: New York Times}

Item 1) China and Europe Fail to Resolve Dispute over Textiles.

Buckley, Chris. New York Times [New York, N.Y] 05 Sep 2005: C.2.

Item 2) Republicans and Obama Can Agree on Criticizing China's Trade Practices: [Foreign Desk].

Landler, Mark. New York Times [New York, N.Y] 22 Nov 2011: A.10.

Item 3) U.S.-China Talks Fail to Produce Major Trade Deal.

Sanger, David. New York Times [New York, N.Y] 09 Apr 1999: 1.

Item 4) A Mining Town's Sullen Peace Masks the Bitter Legacy of China's Labor Strategy.

Eckholm, Erik. New York Times [New York, N.Y] 14 Apr 2002: 1.8.

Item 5) China Uses Rules On Global Trade To Its Advantage: [Business/Financial Desk].

Bradsher, Keith. New York Times [New York, N.Y] 15 Mar 2010: A.1.

Item 6) Beijing Tries to Lift Economic Standards in Its West.

Smith, Craig. New York Times [New York, N.Y] 07 Nov 2000: C.1.

Item 7) Across Asia, Beijing's Star Is in Ascendance: CHINA'S REACH: Trading Influence.

Perlez, Jane. New York Times [New York, N.Y] 28 Aug 2004: A.1.

Item 8) China Imposes New Tariffs on U.S. Vehicles: [Business/Financial Desk].

Bradsher, Keith. New York Times [New York, N.Y] 15 Dec 2011: B.1. 